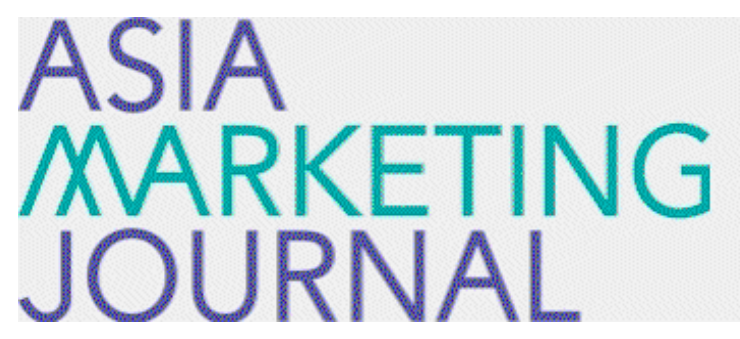

ASIA MARKETING JOURNAL

Volume 8 | Issue 1

Article 1

\title{
4-25-2006
}

\section{고려상표군을 반영한 준거가격효과의 모형화}

Kwang Pil Chang

Follow this and additional works at: https://amj.kma.re.kr/journal

Part of the Marketing Commons

\section{Recommended Citation}

Chang, Kwang Pil (2006) "고려상표군을 반영한 준거가격효과의 모형화," Asia Marketing Journal: Vol. 8 : Iss. 1 , Article 1.

Available at: https://doi.org/10.53728/2765-6500.1159

This Article is brought to you for free and open access by Asia Marketing Journal. It has been accepted for inclusion in Asia Marketing Journal by an authorized editor of Asia Marketing Journal. 


\section{고려상표군을 반영한 준거가격효과의 모형화: Empirical Bayes \& Latent Class Approach*}

\section{Modeling the Effect of Consideration Set-Based Reference Price: Empirical Bayes \& Latent Class Approach}

장 광 필(Chang, Kwangpil)**

다양한 선행연구에서 준거가격효과는 실증적 지지를 받아온 것이 사실이다. 그러나 대부분의 선행 연구에서 간과된 부분은 설명되지 않은 소비자 반응의 이질성이 준거가격에 반영되어 실재하지 않는 효과가 마치 유의한 것으로 나타날 수도 있다는 것이다(Chang, Siddarth, and Weinberg 1999; Bell and Lattin 2000). 또 다른 차원의 이질성으로서, 고려상포군의 이질성이 반영되지 않을 경우 모델에 포함된 변수의 모수추정치에 왜곡현상이 나타날 수 있음을 Meyer and Kahn(1991)이 지적한 바 있 다. 이러한 선행연구의 문제점을 고려하여 이 연구에서는 반응의 이질성과 고려상표군의 이질성을 모 두 반영한 모델을 적용함으로써 보다 정확한 준거가격효과의 추정을 시도하였다. 또한 소비자별 고려 상표군의 이질성을 반영한 준거가격 측정치를 새롭게 제안하여 검증하고자 하였다. 실증분석결과, 제 안된 준거가격 측정치가 선행연구에서 사용한 측정치에 비해 모델적합도와 예측타당성을 향상시키는 것으로 나타났다. 이 결과는 준거가격 형성과정에도 고려상표군의 이질성이 반영됨을 실증하는 것이 다. 고려상표군의 이질성이 반영될 경우, 선행연구의 준거가격 측정치에 비해서, 제안된 준거가격 측 정치의 평균이 높게 나타났으며, 표준편차는 감소한 것으로 나타났다.

이 연구에서 제안된 측정치의 실제적인 적용 측면을 본다면, Greenleaf(1995)의 연구에서처럼, 최적 의 가격정책이 손실회피(loss aversion)의 크기, 즉, 준거의존(reference-dependent) 모델상의 준거가 격에 의존한다면 제안된 측정치가 유용하게 사용될 수 있을 것으로 판단된다. 최대화해야 할 이익함 수에 포함된 준거가격 측정치의 정확성이 최적가격결정을 좌우하기 때문이다. 따라서, 준거가격모델 에 근거하여 최적가격을 추정할 경우. 모델자체에 고려상표군과 반응의 이질성을 반영할 뿐만 아니 라. 준거가격 측정치 또한 고려상표군의 이질성을 반영하는 것이 바람직할 것으로 판단된다.

핵심개념: 준거가격. 손실회피. empirical bayes approach, latent class approach

* 이 논문은 2002 년도 서울시립대학교 학술연구조성비에 의하여 연구되었음.

** 서울시립대학교 경영학부 부교.수(kpchang@uos.ac.kr) 


\section{I. 서 론}

소비자는 마음속에 내재된 준거가격(internal reference price)과 실제 관측된 가격을 비교함 으로써 브랜드를 선택한다는 가설을 검증하기 위해 선행연구에서 다양한 모델이 제안되고 실증분석에 적용되었다. 이러한 연구에서는 모 델이 가정하는 바, 예컨대, 준거가격 측정치의 형태(linearly lagged prices vs. exponentially smoothed past prices), 분석단위(brand- specific vs. category-specific reference price) 등의 차이 는 있지만, 공통적으로 과거의 가겨정책이 준거 가격 형성에 영향을 미치는 것으로 가정하고 있 으며, 구매시점 이전에 관측한 일련의 가격들이 준거가격의 중요한 예측치(predictor)임을 실증하 고 있다(Kalyanaram and Winer 1995; Kalwani, Yim, Rinne and Sugita 1990).

준거가격효과에 대한 실증연구의 대부분은 브 랜드선택모형(multinomial logit model)의 효용 함수에 준거가격 측정치(measure)를 포함시켜 그 효과를 추정하는 방식을 취하고 있는데, 두 가지 대표적인 모형으로서, 스티커쇼크(sticker shock) ${ }^{1 /}$ 모형(Winer 1986) 과 준거의존(referenodependent) 모형(Hardie, Johnson, and Fader 1993)이 주로 사용된 것으로 나타났다(Briesch, Krishnamurthi, Mazumdar, and Raj 1997). 스 티커쇼크모형은 소비자는 브랜드별로 서로 다 른 준거가격(brand-specific reference price)을 갖고 실제가격 뿐만 아니라 실제가격과 준거가 격과의 차이도 고려해서 브랜드를 선택한다는
가정 하에 효용함수에 그 차이를 포함시킨 모형 을 의미한다. 반면에, 준거의존모형은 프로스팩드 이론(Prospect Theory) (Kahneman and Tversky 1979)에 근거해서, 소비자는 제품군 전체에 대 해 하나의 준거가격(category-specific reference price)을 갖고 있고. 실제가격과 준거가격의 차 이에 대해 비대칭적 반응(Tversky and Kahneman 1991), 즉, 손실회퍼(loss aversion)현상을 보인다는 가설을 반영한 모형이다. Briesch et al.(1997)은 전술한 두 가지 모형을 기본으로 몇 가지 변형 된 모형을 통해 준거가격 측정치들을 비교하는 실증분석을 함으로써 준거가격 형성과정을 이 해하고자 하였다.

두 가지 모형을 실제 데이터에 적용하는데 있 어서 주의를 요하는 부분은, Chang, Siddarth, and Weinberg(1999)와 Bell and Lattin(2000) 이 지적했듯이, 소비자 반응의 이질성(response heterogeneity)을 반영하는 것이다. 반응의 이질 성을 무시한 실증모델을 적용할 경우, 실재하지 않는 준거가격효과가 유의한 것으로 추정될 수 있기 때문이다. 그 예로서, 소비자 반응의 이질 성을 무시한(즉, 동질성을 가정한) 스티커쇼크 모형을 적용했을 때 유의하게 나타난 준거가격 효과가 이질성을 반영할 경우 사라지는 것으로 나타났으며(Chang et al. 1999), 준거의존모헝 의 경우 손실회피의 정도가 사라지진 않지만 상당히 감소하는 것으로 보고된 바 있다(Bell and Lattin 2000). 따라서 준거가격효과의 검증 은 소비자반응의 이질성을 반영한 모형 상에서 그 효과가 유의한 가를 확인하는 절차가 필요 한 것으로 판단된다.

1) sticker price와 준거가격과의 차이에서 오는 충격이란 의미에서 sticker shock이라 함. 
위에 언급한 반응의 이질성과는 다른 차원의 이질성으로서, 준거가격효과의 선행연구에서 무 시된 부분은, 고려상표군의 이질성(consideration set heterogeneity)이다(한상만 (1998) 과 장광필, 이성호 (2003)는 예외). 즉. 브랜드선택에 선행 해서 소비자별로 서로 다른 고려상표군을 형성 함에도 불구하고, 연구에 포함된 모든 브랜드를 고려한다는 가정(소비자별로 동일한 고려상표 군 가정)하에 준거가격효과를 추정한 것이다. Meyer and Kahn(1991) 과 Siddarth. Bucklin. and Morrison(1995)이 지적했듯이. 연구자가 정 의한 시장 내의 모든 브랜드 중 단지 소수의 브랜드만 소비자가 고려할 경우, 이를 무시한 브랜드선택모형을 적용하게 되면 모형에 포함 된 변수의 효과추정치(모수추정치)와 고유절편 이 왜곡되는 것으로 나타났으며 (장광필 2003), 준거가격효과의 추정에 있어서도, 마찬가지의 왜곡 현상이 나타날 것으로 예상된다. 따라서, 준거가격효과의 보다 엄밀한 추정을 위해서는 소비자반응의 이질성뿐만 아니라. 고려상표군의 이질성도 반영하는 것이 중요할 것으로 판단된 다. 한상만(1998)의 연구에서와 같이 두 가지 이질성을 모두 반영한 모형 ${ }^{2}$ 을 적용한 경우에 야 비로서 준거가격호과의 유의성을 확인할 수 있기 때문이다.

이 연구에서는 두 가지 이질성을 반영한 모형 을 적용함과 동시에 고려상포군의 이질성을 반 영한 준거가격 측정치의 타당성을 검증하고자
한다. 이 연구와 한상만(1998)의 연구 모두 2 단 계 모형(고려상표군형성과 브랜드선택의 2단계) 을 적용한 공통점을 갖고 있으나 다음과 같은 차 이점을 갖고 있다. 첫째, 고려상표군 형성과정의 모형화가 다르다. 한상만(1998)은 Bronnenberg and Vanhonacker(1996)의 모형에 근거해서 고 려상표군 형성과정을 보상적인(compensatory) 방식에 따라 모형화한 반면에 이 연구에서는 Siddarth et al.(1995)의 모형에 근거해서 비보 상적인(non-compensatory) 방식으로 모형화하 였다. 둘째, 한상만(1998)의 연구는 Hardie et al.(1993)의 준거가격 측정치를 그대로 적용하 여 고려상표군 형성단계에서의 준거효과를 추 정한 반면에 이 연구의 초점은 고려상표군의 이질성을 반영한 준거가격 측정치를 사용하여 브랜드 선택단계에서의 준거가격효과를 검증하 는 것이다. 즉. 소비자가 과거 구매행태에 따라 고려상표군을 형성한다면 같은 정보를 사용하 여 준거가격을 형성할 것이고. 그렇게 형성된 준거가격이 궁극적으로 브랜드선택에 영향을 미칠 것이라는 가설을 검증하는 것이다. 이 연 구에서는 두 가지 대표적인 준거가격모형중 소 비자반응의 이질성을 반영한 후에도 준거가격 효과가 유의한 것으로 보고된(Bell and Lattin 2000 ) 준거의존모형을 중심으로. 소비자 패널자 료를 사용하여, 고려상표군의 이질성을 반영한 준거가격 측정치의 타당성을 검증하고자 한다.

이 논문의 구성은 다음과 같다. 제 II 장에서

2) 준거가격효과 자체에 관한 연구는 아니지만 Chiang, Chib, and Narasimhan(1999)은 고려상표군과 반응의 이질성을 모두 반영한 모형을 제안한 바 있다. 그러나 이 모형은 가능한 모든 고려상표군을 전제하고 있기 때문에. 연구대상이 되는 브 랜드의 수 $(n)$ 가 늘어나면 서로 다른 고려상표군의 수 $\left(2^{n}-1\right)$ 가 기하급수적으로 증가하게 된다. 따라서 많은 수의 브랜드 가 포함된 제품군을 대상으로 한 실증분석에는 적합하지 않은 것으로 판단된다. 또한, 장광필, 이성호(2003)의 연구는 고 려상표군의 이질성만 반영한 모형을 적용한 한계를 가지고 있다. 
는 모형을 제안하고, 제 피장에서는 실증분석과 모형 추정방식을 설명한다. $\mathrm{V}$ 장에서는 실증분 석결과를 요약하고, 마지막 $\mathrm{V}$ 장에서는 결론과 함께 향후 연구방향을 제시한다.

\section{II. 제안된 모형}

이 장에서는 소비자 반응의 이질성과 고려상 표군 형성과정을 반영한 모형을 제안하고, 실증 분석에서 사용할 준거가격 측정치를 설명하고 자 한다. 제안된 모형의 이해를 돕기 위해 최종 적인 브랜드 선택단계를 먼저 설명하고, 이에 선행하는 고려상표군 형성단계를 다음에 설명하 고, 준거가격 측정치를 마지막으로 설명하였다.

\section{1. 브랜드 선택단계}

제안된 모형은 브랜드 선택단계에서의 소비자 반응의 이질성은 Kamakura and Russell(1989) 의 latent class approach를 적용하고, 고려상표 군 형성과정은 Siddarth et al.(1995)의 비보상 적 방식을 적용한 모형이다. 세분시장 ${ }^{3)} S$ 에 속 한 소비자 $h$ 가 브랜드 $j$ 를 선택할 확률은 연구 자가 정의한 시장 내의 모든 브랜드로 구성된 풀셋(full set)과 소수의 브랜드로 구성된 고려 상표군(consideration set)에서 브랜드 $j$ 를 선택 할 각 각의 확률을 혼합(probabilistic mixture) 한 것으로 다음과 같이 정의한다(Siddarth et al. 1995).

$$
P_{s t}^{h}(j)=\lambda p c_{s t}^{h}(j)+(1-\lambda) p f_{s t}^{h}(j)
$$

여기서 $p c_{s t}{ }^{h}(j)\left(p f_{s t}{ }^{h}(j)\right)$ 는 세분시장 $s$ 에 속한 소비자 $h$ 가 구매시점 $t$ 에 고려상표군(풀셋) 으로부터 브랜드 $j$ 를 선택할 확률을 나타내면 $\lambda(1-\lambda)$ 는 고려상표군(풀셋)에서 선택할 확률을 의미한다. 풀셋으로부터 브랜드 $j$ 를 선택할 확 률, $p f_{s t}^{h}(j)$,는 multinomial logit모형에 따라 다 음과 같이 정의한다.

$$
\not f_{s t}^{h}(j)=\frac{\exp \left(U_{s i t}^{h}\right)}{\sum_{k} \exp \left(U_{s k t}^{h}\right)}
$$

동일한 방식으로 고려상표군으로부터 브랜드 $j$ 를 선택할 확률, $p c_{s t}{ }^{h}(j)$,는 다음과 같이 정의 한다.

$$
p c_{s t}^{h}(j)=\frac{\theta_{j t}^{h} \exp \left(U_{s i t}^{h}\right)}{\sum_{k} \theta_{k t}^{h} \exp \left(U_{s k t}^{h}\right)}
$$

여기서 브랜드 $j$ 가 소비자 $h$ 의 고려상표군에 포함되면 $\theta_{j{ }^{h}}{ }^{h}=1$, 아니면 0 의 값을 갖는다. 따 라서 브랜드 $j$ 가 고려상표군에 포함되지 않는 경우 $p C_{s t}{ }^{h}(j)=0$ 이 된다. 소비자별 고려상표군 형성과정은 다음 절에서 상술하기로 한다. 수식 (2)와 (3)에서 $U_{s i t}^{h}$ 는 세분시장 $s$ 에 속한 소비 자 $h$ 의 구매시점 $t$ 에서의 브랜드 $j$ 에 대한 효 용(Utility)을 나타내며, Hardie et al.(1993)의 준거의존모형에 따라 준거가격효과의 손실회피 현상을 검증하기 위해 다음과 같이 정의한다.

3) 세분시장별로 모수를 달리 가정함으로써 소비자 반응의 이질성을 반영함. 


$$
\begin{aligned}
U_{s j t}^{h}= & \beta_{j}+\beta_{s 1} B L O Y_{j}^{h}+\beta_{s 2} L B P_{j t}^{h} \\
& +\beta_{s 3} P G A I N_{j t}+\beta_{s 4} \text { PLOSS }_{j t} \\
& +\beta_{55} \text { PROMO }_{j t}
\end{aligned}
$$

여기서.

$B L O Y_{j}^{h}$ : 변수초기화 기간(initialization period) 중 소비자 $h$ 가 브랜드 $j$ 를 구매한 비 율로서 Lattin과 Bucklin(1989)의 정 적인(static) 상표충성도 측정치와 동 일하다.

$L B P_{j k}^{h}$ : 구매시점 $t-1$ 에 구매한 브랜드와 브랜 드 $j$ 가 동일하면 1 , 아니면 0 .

$P G A I N_{j t}$ : 브랜드 j의 실제가격(shelf price)이 준 거가격보다 낮으면 준거가격-실제가 격, 아니면 0 .

$P L O S S_{\text {t }}$ : 브랜드 $j$ 의 실제가격(shelf price)이 준 거가격보다 높으면 준거가격-실제가 격, 아니면 0 .

$P R O M O_{j t}$ : 구매시점 $t$ 에 브랜드 $j$ 의 매장내 디스 플레이가 있으면 1 , 아니면 0.

여기서, $\beta_{S 4} / \beta_{S 3}$ 가 1보다 통계적으로 유의하게 크면, 즉, 손실에 대한 반응이 이득에 대한 반 응보다 크면, 손실회피의 가설이 지지되는 것 이다. $\beta_{S}$ 가 셰분시장 별로 다른 것(segmentspecific)은 소비자 반응의 이질성을 반영하는 것이다. 다음 절에서는 고려상표군 형성과정의 모형화를 설명하고 이어서 준거가격 측정치의 설명을 하고자 한다.

\section{2 고려상표군 형성단계}

Siddarth et al.(1995)의 방식에 따라 브랜드 별 선호도를 추정하고, 고려상표군 포함여부를
판단하는 임계치를 추정하여. 임계치보다 높은 선호도를 갖는 브랜드만 고려상표군에 포함시 킨다. 브랜드별 선호도의 선험분포(sample-wide prior distribution of brand preference)로 부터 소비자 개개인의 브랜드별 선호도의 사후분포 를 추정하는 절차는 다음과 같은 경험적 베이 즈(empinical bayes)방식을 적용하였다.

\section{2 .1 브랜드 선호도의 선험분포}

소비자의 과거(모수추정기간 이전의 변수 초 기화기간) 브랜드 선택행동이 브랜드에 대한 선 호를 나타내며(i.e., revealed preference) 실제 고려한 브랜드에 관한 정보를 제공한다는 가정 하에 브랜드별 선호도, $\left\{r p_{j}^{h}\right\}$ 의 선험분포를 다음 과 같은 Dirichlet분포로 가정한다(Goodhardt. Ehrenberg, and Chatfield 1984).

$$
D(\boldsymbol{r p} \mid \boldsymbol{\alpha})=\frac{\Gamma(S)}{\prod_{j=1}^{J} \Gamma\left(\alpha_{j}\right)} \prod_{j=1}^{J} r p_{j}^{\left(\alpha_{j}-1\right)}
$$

여기서, $S=\alpha_{1}+\alpha_{2}+\ldots . . .+\alpha_{n}$ 이다. Dirichlet분 포는 브랜드 $n$ 개의 시장인 경우 $n$ 개의 모수, $\alpha_{l}$, $\alpha_{2}, \ldots . . . . ., \alpha_{n}$ 로 나타낼 수 있으며. 브랜드 $j$ 에 대 한 선험적 선호도는 $\alpha / \mathrm{S}$ 로 정의된다. 소비자 $h$ 가 변수 초기화기간에 브랜드 $j$ 를 구매한 회 수를 $r_{j}^{h}$, 전체 구매회수를 $m^{h}$ 이라고 할 때, 연 구에 포함된 모든 소비자의 자료를 근거로 최 우도법을 통해 $\{\alpha\}$ 를 추정하게 된다(구체적인 추정방법은 Kalwani, Meyer, and Morrison (1994) 논문 p73-74의 appendix 참조). 


\section{2 .2 소비자별 브랜드 선호도의 사후분포}

변수 초기화기간의 자료로 추정한 선험분포의 모 수 $\{\alpha\}$ 를 근거로 모수추정기간(calibration period) 중 구매시점 $t$ 에 브랜드 $j$ 를 구매하면 Bayes rule에 따라 다음과 같이 $\left\{r p_{i t}^{h}\right\}$ 의 기대치를 최 신화(update)한다(구매시점을 구분하기 위해 시간 $t$ 를 아래첨자로 사용).

$$
E\left[r p_{j t}^{h} \mid r_{j t}^{h}, m_{t}^{h}, \alpha, S\right]=\frac{\alpha_{j}+r_{j t}^{h}}{S+m_{t}^{h}}
$$

여기서.

$$
\begin{aligned}
& r_{j t}^{h}=r_{j t-1}^{h}+1 \\
& m_{t}^{h}=m_{t-1}^{h}+1
\end{aligned}
$$

구매시점 $t+1$ 에 임계치 $\delta$ 와 $E\left(r p_{j t}^{h}\right)$ 를 비교 해서 $E\left(r p_{j t}{ }^{h}\right)>\delta$ 인 경우, 즉. 브랜드 $j$ 의 선호도 가 일정수준을 넘을 때 브랜드 $j$ 가 소비자 $h$ 의 고려상표군에 포함되는 것으로 간주한다. $\delta$ 는 브랜드 선택모형의 모수와 함께 grid search ${ }^{4)}$ 방 식을 통한 최우도법으로 추정한다. 수식 (6)은 소비자 $h$ 의 브랜드 선호도가 구매시점에 따라 변화되는 것을 반영하고 있으며(따라서. 장기간 브랜드 $j$ 를 구매하지 않는 경우 고려상표군에 서 탈락), 동시에 소비자별 절대 구매빈도수의 차이도 반영하고 있다. 즉, 구매빈도수가 낮은 경우, 선험분포에 가까운 브랜드 선호도를 갖게
되고 $(\alpha / S)$, 반대의 경우, 소비자의 실제 구매 비율 $\left(r_{j t}^{h} / m_{t}^{h}\right)$ 에 가까운 선호도를 갖게된다.

\section{3 고려상표군을 반영한 준거가격의 측 정치}

준거가격효과의 이론적 배경으로 자주 인용되 는 Helson(1964)의 적응수준이론에 따르면, 적 응수준(adaptation level)은 특정 제품군에서 접 할 수 있는 서로 다른 자극의 크기와 빈도수, 즉, 분포의 함수로 가정하고 있다. 준거가격과 관련하여 해석하면, 제품군내에서 관측되는 다 양한 가격(크기)과 그 가격에 노출된 빈도수에 따라 적응수준, 즉, 준거가격이 결정된다고 해 석할 수 있다. 프로스펙트이론(Kahneman and Tversky 1979)과 같이 제품군내에 하나의 준거 가격(category-specific reference price)을 가정 하는 경우, 가장 단순한 형태의 준거가격 측정 치로 최근 구매한 브랜드의 구매 당시 가격을 사용하거나(Bell and Lattin 2000), 또는 최근 구매한 브랜드의 현재 가격을 사용할 수 있다 (Hardie et al. 1993). 그러나 이러한 준거가격 의 측정치는 지나치게 단순하고 편의주의적인 것으로 판단된다. 즉. 소비자가 과거에 관측했 을 만한 다양한 가격의 노출 빈도수를 무시하 고, 최근 구매한 브랜드의 가격에 단 일회의 노 출로 적응하게 된다는 가정이다. 대안으로서 브 랜드별 구매비율을 가중치로 최근 구매시점의 경쟁가격을 평균한 측정치를 생각할 수 있다 (Briesch et al, 1997). 그러나 소비자 개개인의

4) 먼저 임의의 델타값을 가정하고 그 값에 따라 고려상표군을 정의하고 다른 모수를 최우도법을 통해 추정한다. 다시 새로 운 델타값을 가정하고 마찬가지 방법으로 모수 추정을 반복하여 likelihood function값을 최대화시키는 델타값과 기타 모 수를 추정하는 방식이다. 
단순 구매비율은 절대 구매빈도수를 반영하지 못하는 문제점을 갖고 있다. 즉, 2 회 중 1 회 구 매와 10 회 중 5 회 구매가 동일한 구매비율로 간주되기 때문이다. 이러한 한계점을 감안하여. 이 연구에서는 2.2절 고려상표군 형성과정에 사 용된 브랜드별 선호도의 사후분포를 준거가격 측정치 추정에 사용하고자 한다. 2.2.2.항에서 설명한 바와 같이 경험적 베이즈 방식으로 추 정된 선험분포의 모수와 소비자 개개인의 구매 빈도수로 조합된 사후분포는 전술한 문제점을 해결함과 동시에 Helson(1964)의 이론을 반영 할 수 있는 측정치로 판단된다. 따라서 수식(4) 에 포함되는 준거가격의 측정치는 다음과 같이 정의하였다.

$$
\operatorname{RPRICE}_{t}^{h}=\sum_{j} E\left(r p_{j t}^{h}\right) \cdot P R I C E_{j(t-1)}
$$

여기서 $R P R I C E_{t}^{h}$ 는 소비자 $h$ 의 구매시점 $t$ 의

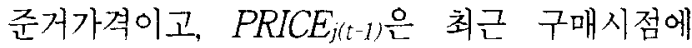
관측된 브랜드 $j$ 의 실제가격을 나타낸다.

\section{III. 실증분석}

\section{1 자료}

데이터는 1986년부터 1988년까지 South Dakota Sioux Falls지역의 요구르트제품군의 패널자료 를 사용했다. 초기 61 수간의 자료는 변수의 초 기화에 사용했고, 이후 52주간의 자료는 모수추 정(calibration)과 타당성평가(validation)에 사 용하였다. 전체 연구기간동안 적어도 4 주에 1 회 이상 매장을 방문한 패널 중에서 초기 61 주간 과 모수추정기간에 각각 적어도 1 회 이상 요구 르트를 구매한 599명의 패널이 연구에 포함되 었다. 이 중 400 명 (3852 records)을 무작위 추 출하여 모수추정을 하고 나머지 199명(1961 records)에 대하여 타당성평가(validation)를 실 시하였다. 매출(unit) 기준 $89 \%$ 에 해당하는 상 위 7 개 브랜드를 대상으로 실증분석을 실시하 였고, 이 브랜드들의 시장점유율과 평균가격은 〈표 1)에 제시된 바와 같다.

〈표 1〉 브랜드별 시장점유율과 평균가격

\begin{tabular}{|c|c|c|}
\hline 브랜드 & 시장점유율 & 평균가격 per ounce \\
\hline Yoplait & 0.19 & 10.13 \\
\hline Weight Watcher & 0.12 & 7.65 \\
\hline Dannon & 0.08 & 8.50 \\
\hline Nordica & 0.29 & 6.67 \\
\hline Q.C. & 0.03 & 5.19 \\
\hline W.B.B & 0.17 & 5.38 \\
\hline Private Label & 0.11 & 4.81 \\
\hline
\end{tabular}




\section{2 추정한 모형}

선행연구에서 사용한 모형과 이 연구에서 제안한 모형과 비교하기 위해서 단계적으로 다음과 같은 모형을 추정하였다. 각 각의 모 형은 준거가격 포함여부, 고려상표군의 이질 성 반영여부, 소비자 반응의 이질성 반영여부, 준거가격 측정치의 종류 (최근 구매시점에 구 입한 브랜드의 가격 vs. 고려상표군을 반영한 준거가격)로 구분되며 (표 2〉에 제시된 바와 같다.

\subsubsection{MNL모형}

고려상표군과 반응의 이질성을 무시한 모형으
로서 준거가격이 제외된 다음과 같은 효용함수 와 수식(2)의 선택확률을 적용하였다.

$$
\begin{aligned}
U_{j t}^{h}= & \beta_{j}+\beta_{1} B L O Y_{j}^{h}+\beta_{2} L B P_{j t}^{h} \\
& +\beta_{3} P_{R I C E_{j t}}+\beta_{4} \text { PROMO }_{j t}
\end{aligned}
$$

\subsubsection{MNLRD모형}

고려상표군과 반응의 이질성을 무시한 모형으 로서 준거가격 의존효과(reference-dependent effect)를 포함한 다음과 같은 효용함수와 수식 (2)의 선택확률을 적용하였다.

$$
U_{j t}^{h}=\beta_{j}+\beta_{1} B L O Y_{j}^{h}+\beta_{2} L B P_{j t}^{h}
$$

\begin{tabular}{|c|c|c|c|c|}
\hline 모형 & 모수의 갯수 & $\begin{array}{c}\text { 반응의 이질성 } \\
\text { 포함여부 }\end{array}$ & $\begin{array}{l}\text { 고려상표군 } \\
\text { 포함여부 }\end{array}$ & 준거가격 \\
\hline MNL & $\begin{array}{c}10 \\
\text { (절편 6, 변수 4) } \\
\end{array}$ & $X$ & $X$ & 불포함 \\
\hline MNLRD & $\begin{array}{c}11 \\
(\mathrm{MNL}+\text { 준거가격 }) \\
\end{array}$ & $X$ & $X$ & $\begin{array}{c}\text { 최근 구매한 브랜드 } \\
\text { 가격 }\end{array}$ \\
\hline CSET & $\begin{array}{c}12 \\
(\mathrm{MNL}+\delta+\lambda)\end{array}$ & X & 0 & 불포함 \\
\hline CSETRD & $\begin{array}{c}13 \\
(\mathrm{CSET}+\text { 준거가격 })\end{array}$ & $X$ & 0 & $\begin{array}{c}\text { 최근 구매한 브랜드 } \\
\text { 가격 }\end{array}$ \\
\hline CSETRD* & $\begin{array}{c}13 \\
(\mathrm{CSET}+\text { 준거가격 })\end{array}$ & $X$ & 0 & $\begin{array}{c}\text { 고려상표군을 반영 } \\
\text { 한 준거가겨 }\end{array}$ \\
\hline CSEG & 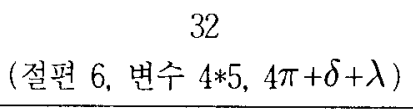 & 0 & 0 & 불포함 \\
\hline CSEGRD & $\begin{array}{c}37 \\
\text { (CSEG+5준거가격) }\end{array}$ & 0 & 0 & $\begin{array}{c}\text { 최근 구매한 브랜드 } \\
\text { 가격 }\end{array}$ \\
\hline CSEGRD* & $\begin{array}{c}37 \\
(\mathrm{CSEG}+5 \text { 준거가격 })\end{array}$ & 0 & 0 & $\begin{array}{c}\text { 고려상표군을 반영 } \\
\text { 한 준거가격 }\end{array}$ \\
\hline
\end{tabular}

〈표 2〉 추정된 모형별 특징 


$$
\begin{aligned}
& +\beta_{3} \text { PGAIN }_{j t}+\beta_{4} \text { PLOSS }_{j t} \\
& +\beta_{5} \text { PROMO }_{j t}
\end{aligned}
$$

여기서, PGAIN과 PLOSS에 포함된 준거가 격은 다음과 같이 정의하였다.

$$
\operatorname{RPRICE}_{t}^{h}=\operatorname{PRICE}_{c(t-1)}
$$

여기서. $P R I C E_{c(t-1)}$ 은 최근 구매시점에 구매 한 브랜드의 구매 당시 가격 ${ }^{5)}$ 을 나타낸다.

\subsubsection{CSET모형}

고려상표군의 이질성만 반영한 모형으로서 준 거가격이 제외된 수식(10)의 효용함수와 수식 (1)의 선택확률을 적용하였다.

\subsubsection{CSETRD모형}

고려상표군의 이질성만 반영한 모형으로서 준 거가격 의존효과를 포함한 수식(11)의 효용함 수와 수식(1)의 선택확률을 적용하였으며, 준거 가격은 수식(12)에 정의된 바와 같다.

\subsubsection{CSETRD*모형}

CSETRD모형과 마찬가지로 고려상표군의 이 질성만 반영한 모형으로서 준거가격 의존효과
를 포함한 수식(11)의 효용함수와 수식(1)의 선택확률을 적용하였다. 차이점은 준거가격을 수식(12)가 아닌 수식(9)에 따라, 고려상표군의 이질성을 반영하여 정의하였다.

\subsubsection{CSEG모형}

고려상표군과 반응의 이질성은 반영하였으나 준거가격은 포함하지 않은 모형으로서 다음과 같은 효용함수와 수식(1)의 선택확률을 적용하 였다.

$$
\begin{aligned}
U_{s j t}^{h}= & \beta_{j}+\beta_{s 1} B L O Y_{j}^{h}+\beta_{s 2} L B P_{j t}^{h} \\
& +\beta_{s 3} P_{R I C E_{j t}+\beta_{s 4}} P R O M O_{j t}
\end{aligned}
$$

\subsubsection{CSEGRD모형}

고려상표군과 반응의 이질성을 반영하고 수식 (4)의 효용함수를 적용하였다. 준거가격은 수식 (12)에 정의된 바와 같다.

\subsubsection{CSEGRD*모형}

이 연구에서 제안된 모형으로서 고려상표군과 반응의 이질성을 반영함과 동시에 수식(9)에 정의된 바와 같이 고려상표군의 이질성을 반영 한 준거가격을 포함하여 수식(4)의 효용함수를 적용하였다.

5) Hardie et al.(1993)은 준거가격의 측정치로 구매시점 $t-1$ 에 구때한 브랜드의 현재가격을 사용하였다. Briesch et al.(1997)은 그러한 측정치를 자극기반(stimulus-based) 준거가격이라고 정의하였다. 반면에. Bell and Lattin(2000)은 최 근 언구에서 기억기반(memory based) 준거가격, 즉. 구매시점 $t-1$ 에 지불한 가격을 측정치로 사용해서 12 개의 제품군을 대상으로 모형을 추정한 결과, 가극에 근거한 준거가격보다 설명력이 우수함을 보였다. 


\section{3 모수추정}

Kamakura and Russell(1989)의 latent class approach를 적용해서 다음과 같은 $\log$-likelihood (LL)를 최대화함으로써 모수를 추정하였다.

$$
L L=\sum_{h=1}^{H} \ln \left[\sum_{s=1}^{S} \pi_{s} \prod_{t=1}^{T^{h}} P_{s t}^{h}(c)\right]
$$

여기서 $\sum_{s} \pi_{s}=1$ 이고, $\pi_{s}$ 는 추정해야할 모수이 며, 선험적으로 가정한 세분시장의 상대적 크기 를 나타낸다. $H$ 는 연구에 포함된 총 패널의 수. $T^{h}$ 는 소비자 $h$ 의 총 구매회수, $S$ 는 세분시장의 수, $c$ 는 실제 선택한 브랜드를 나타낸다. 최적 의 세분시장 수는 세분시장 수가 증가함에 따 라 변하는 모형적합도를 보고 판단하였다. 즉, 세분시장의 수가 증가함에도 불구하고 모형적 합도의 증가가 미미하다면 그 때까지의 세분시 장 수를 적정하다고 간주하였다(Kamakura and Russell 1989; Bucklin and Gupta 1992). 모형 적합도는 세분시장수가 증가함에 따라 늘어나 는 모수에 대한 페널티를 반영한 BIC(bayesian information criteria $)^{6)}$ 로 측정하였다.

\section{4 타당성평가}

수식(14)를 최대화하여 추정한 $\pi_{s}$ 는 소비자 $h$ 가 세분시장 $s$ 에 속할 선험적 확률로 해석할 수 있다. 따라서 구매시점 $t$ 에 소비자 $h$ 가 브랜 드 $c$ 를 선택한 것을 관측한 후 세분시장 $s$ 에 속할 사후 확률은 Bayes rule에 따라 다음과
같이 정의된다.

$$
W_{s(t+1)}^{h}=\frac{W_{s t}^{h} \cdot P_{s t}^{h}(c)}{\sum_{s=1}^{S} W_{s t}^{h} \cdot P_{s t}^{h}(c)}
$$

여기서 $W_{s l}{ }^{h}=\pi_{s}$ 이고 $c$ 는 선택된 브랜드를 나 타낸다. 따라서 세분시장과 관계없이 브랜드 $j$ 를 선택할 무조건확률은 다음과 같다.

$$
P_{t}^{h}(j)=\sum_{s=1}^{S} W_{s t}^{h} \cdot P_{s t}^{h}(j)
$$

수식(16)에 정의된 무조건확률을 적용하여. 유보샘플의 log-likelihood와 hit-ratio를 계산하 여 모형의 타당성평가를 하였다.

\section{IV. 실증분석결과}

반응의 이질성을 반영하지 않은 모형 (MNL, MNLRD, CSET, CSETRD, CSETRD*)의 모 형적합도는 〈표 3〉에 나타난 바와 같다. 대부분 의 선행연구와 마찬가지로 반응의 이질성을 반 영하지 않은 모형에서의 준거가격 의존효과는 유의한 것으로 나타났다. 또한 고려상표군의 이 질성을 반영한 모형 모두 MNL, MNLRD모형 보다 모형적합도가 높은 것으로 나타났다. 즉, 소비자별로 서로 다른 고려상표군을 반영하는 것이 실제 브랜드선택행동을 보다 잘 설명하 는 것으로 보여진다. 특히 CSETRD*는 CSETRD

6) $\mathrm{BIC}=L L-(p / 2) * \ln (N), p$ 는 모수의 개수, $N$ 은 총 자료의 수(observations). 
〈표 3〉 반응의 이질성을 무시한 모형의 모형적합도

\begin{tabular}{|c|c|c|c|c|c|}
\hline 모형 & 모수의 갯수 & $\begin{array}{c}\text { Calibration } \\
\text { log-likelihood }\end{array}$ & $\begin{array}{c}\text { Calibration } \\
\text { BIC }\end{array}$ & $\begin{array}{c}\text { Hold-out } \\
\log \text {-likelihood }\end{array}$ & Hit ratio \\
\hline MNL & 10 & -4579.947 & -4621.229 & -2242.495 & $55.93 \%$ \\
\hline MNLRD & 11 & -4563.012 & -4608.422 & -2228.321 & $56.22 \%$ \\
\hline CSET & 12 & -4357.277 & -4406.815 & -2151.950 & $58.09 \%$ \\
\hline CSETRD & 13 & -4349.976 & -4403.642 & -2149.231 & $58.45 \%$ \\
\hline CSETRD $^{*}$ & 13 & -4327.801 & -4381.467 & -2144.323 & $59.36 \%$ \\
\hline
\end{tabular}

〈표 4〉 CSEG모형 세분시장의 수

\begin{tabular}{|c|c|c|c|}
\hline 세분시장의 수 & 모수의 갯수 & $\begin{array}{c}\text { Calibration } \\
\log \text {-likelihood }\end{array}$ & $\begin{array}{c}\text { Calibration } \\
\text { BIC }\end{array}$ \\
\hline 1 & 12 & -4357.277 & -4406.815 \\
\hline 2 & 18 & -4123.113 & -4197.420 \\
\hline 3 & 24 & -4080.514 & -4179.590 \\
\hline 4 & 30 & -3967.620 & -4091.465 \\
\hline 5 & 36 & -3906.299 & -4054.913 \\
\hline 6 & 42 & -3891.828 & -4065.211 \\
\hline $5^{*}$ & 32 & -3914.002 & -4046.104 \\
\hline
\end{tabular}

* 수식(1)의 $\lambda$ 를 세분시장별로 동일하다고 가정한 경우

보다 설명력이 우월한 것으로 나타났다. 이것은 선행연구에서 준거가격 측정치로 주로 사용했 던 최근 구매가격보다 이 연구에서 제안한 고 려상표군의 이질성을 반영한 준거가격 측정치 가 모형적합도를 향상시키며, 설명력이 우수하 다는 것을 입증하는 것이다. 그러나 〈표 3〉에 비 교된 모형의 경우는 설명되지 않은 반응의 이 질성이 준거가격 의존효과로 나타날 수 있다는 점에 유의해야 할 것이다(Chang et al. 1999: Bell and Latten 2000). 보다 엄밀한 준거의존 효과의 검증은 서론에서 설명한 바와 같이 반 응의 이질성과 고려상표군의 이질성을 모두 반 영한 모형을 근거로 해야할 것이다.
고려상표군의 이질성과 반응의 이질성을 모두 반영한 모형으로서, 가장 기본적인 CSEG모형 을 기준으로 세분시장의 수를 결정하는 과정은 〈표 4>에 나타난 바와 같다. 나머지 CSEGRD와 $\mathrm{CSEGRD} *$ 모형도 동일한 방식으로 세분시장의 수를 결정하였다. $\mathrm{BIC}$ 에 따라 5 개의 세분시장 이 최적인 것으로 나타났으며, 3가지 모형의 모 형적합도는 〈표 5)에 나타난 바와 같다. CSEG 모형과 비교할 때 CSEGRD모형은 모수추정 샘 플에서는 적합도가 높은 것으로 보이지만 유보 샘플에서의 적합도(log-likelihood와 hit ratio)는 오히려 낮게 나타났다. 즉, 고려상표군과 반응 의 이질성을 모두 반영한 경우 선행연구에서 
〈표 5〉 고려상표군과 반응의 이질성을 반영한 모형의 모형적합도

\begin{tabular}{|c|c|c|c|c|}
\hline 모형 & 모수의 갯수 & $\begin{array}{c}\text { Calibration } \\
\text { BIC }\end{array}$ & $\begin{array}{c}\text { Hold-out } \\
\log \text {-likelihood }\end{array}$ & Hit Ratio \\
\hline CSEG & 32 & -4046.104 & -1991.500 & $63.23 \%$ \\
\hline CSEGRD & 37 & -4043.224 & -1993.571 & $62.93 \%$ \\
\hline CSEGRD $^{*}$ & 37 & -4033.545 & -1989.073 & $63.64 \%$ \\
\hline
\end{tabular}

〈표 6〉 CSEGRD*모형의 모수 추정치

\begin{tabular}{|c|c|c|c|c|c|}
\hline 변수 & 세분시장 1 & 세분시장 2 & 세분시장 3 & 세분시장 4 & 세분시장 5 \\
\hline$B L O Y$ & $0.192^{*}$ & 9.417 & 3.547 & $0.135^{*}$ & 0.856 \\
\hline$L B P$ & 0.457 & 0.819 & $0.375^{*}$ & 3.277 & 0.467 \\
\hline PGAIN & 0.743 & 0.502 & 0.771 & $0.180^{* *}$ & $0.010^{* *}$ \\
\hline PLOSS & 0.600 & 0.973 & 0.529 & $0.359^{* *}$ & $0.209^{* *}$ \\
\hline PROMO & 1.523 & $1.173^{*}$ & 2.198 & 0.696 & 1.077 \\
\hline $\begin{array}{c}\text { 세분시장 비율 } \\
\pi_{s}\end{array}$ & 0.486 & 0.046 & 0.195 & 0.079 & 0.193 \\
\hline $\begin{array}{c}\text { Mixture } \\
\text { probability } \\
\lambda\end{array}$ & & & 0.385 & & \\
\hline $\begin{array}{c}\text { Threshold } \\
\delta\end{array}$ & & & 0.068 & & \\
\hline
\end{tabular}

${ }^{*} \mathrm{a}=0.05$ 수준에서 유의하지 않음(insignificant)

** $\mathrm{a}=0.05$ 수준에서 두 모수의 비율(PLOSS/PGAIN)이 1 보다 유의하게 크다.

사용한 측정치를 사용한 모형(CSEGRD)의 예측 타당성은 측정치를 사용하지 않은 모형(CSEG) 보다 낮으며, 오히려 overfitting하는 것으로 나 타났다. 반면에. CSEGRD*모형의 경우 모수추 정샘플과 유보샘플에서 모두 CSEG모형보다 모 형적합도가 높게 나타났다. 따라서, 고려상표군 의 이질성을 반영한 측정치를 사용한 모형의 준거가격 의존효과는 유의한 것으로 판단된다.
〈표 6〉은 제안된 모형 CSEGRD*의 모수추정 치를 보여주고 있다. 주목할 점은 준거가격 의

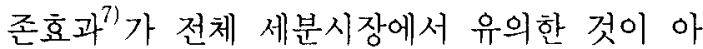
니라 세분시장 4 와 5 , 즉, $27.2 \%$ 의 시장에서만 유의한 것으로 나타났다. 이 결과는 Bell and $\operatorname{Lattin}(2000)$ 의 실증분석 결과와 일치하는 것으 로서 반응의 이질성을 고려하면 준거가격 의존 호과가 감소하지만, 완전히 사라지지는 않는 것

7) Bell and Lattin(2000)의 연구와 마찬가지로 PLOSS 모수추정치의 PGAIN 모수추정치에 대한 비율이 1 이상인 가를 검 정함으로써 준거가격 의존효과의 손실회피 현상을 판별하였다. 두 모수의 비율, $k$ 의 분산행렬은 크라머공리(Kramer's theorem)에 따라 $\left(\partial K / \partial \beta_{i}\right)^{\prime} \Sigma\left(\partial \kappa / \partial \beta_{i}\right)$ 로 계산하였다. 여기서 $\Sigma$ 는 $\beta_{i}$ 의 공분산행렬로서, $\mathrm{i}=P L O S S, P G A I N$ 이다. 
〈표 7〉 $\beta_{j}$ (절편), $\alpha_{j} / \mathrm{S}$ (선험적 선호도), 고려상표군에 포함된 비율

\begin{tabular}{|c|c|c|c|}
\hline 브랜드 & 절편 & $\alpha_{j} / S$ & $\begin{array}{c}\text { 고려상표군에 } \\
\text { 포함된 비율 }\end{array}$ \\
\hline Yoplait & 2.233 & 0.179 & 0.48 \\
\hline Weight Watcher & 1.624 & 0.048 & 0.20 \\
\hline Dannon & 1.379 & 0.148 & 0.37 \\
\hline Nordica & 0.482 & 0.311 & 0.79 \\
\hline Q.C. & 0.404 & 0.053 & 0.19 \\
\hline W.B.B. & 0.347 & 0.131 & 0.57 \\
\hline Private Label & 0.000 & 0.132 & 0.39 \\
\hline
\end{tabular}

으로 보여진다. 모수추정치에 따라 나머지 세분 시장을 해석하면 다음과 같다. 세분시장 1 은 0.486 의 점유율을 가진 가장 큰 세그먼트로서 상표충성도에 따른 구매보다는 프로모션에 민감 한 것으로 보인다. 반면에 세분시장 2 는 가장 작은 세그먼트로서 주로 상표충성도에 따라 구 매하며 프로모션에는 둔감한 것으로 나타났다. 세분시장 3 은 프로모션에 가장 민감한 세그먼트 로서 0.195의 점유율을 갖고 있으며 최근 구매한 브랜드에 대한 충성도는 낮은 것으로 보인다.

〈표 7〉은 CSEGRD*모형 절편의 추정치, 수식 (5)의 Dirichlet 선험분포 모수로 조합된 $\alpha_{j} / S$ (선험적 선호도)와 고려상표군에 포함된 비율 을 나타내고 있다. $\alpha_{j} / S$ 는 변수초기화 단계. 즉. 소비자 패널의 상표선택 행동을 관측하기 전 브랜드별로 고려상표군에 포함될 가능성에 대한 선험적 확률을 나타낸다. 반면에 고려상표 군에 포함된 비율은 브랜드별 $\alpha_{i} / S$ 가 모수추정 기간 동안에 수식 (6), (7), (8)에 따라 최신화 되면서 $\delta$ 보다 큰 횟수의 비율을 계산한 것이다. 비율이 1 이면 $100 \%$ 고려상표군에 포함된 것을 의미한다. 따라서 브랜드별 비율의 합계는 전체
7개 브랜드 중 평균 몇 개의 브랜드를 고려하 는지를 나타내며. 이 연구에서는 2.99개로 나타 났다. Nordica의 경우 가장 큰 시장점유율을 가 진 브랜드로서 고려상표군에 포함된 비율도 $79 \%$ 로서 대부분의 소비자가 구매시 고려하는 브랜드로 보여진다. W.B.B.와 PB 상표를 비교 해보면 선험적 확률은 거의 비슷했지만. 모수추 정기간 동안에 고려상표군에 포함된 비율에서 는 W.B.B.가 $18 \%$ 정도 앞선 것으로 나타났다. 실제 시장점유율의 변화를 모니터하는 것도 중 요하지만, 그러한 변화의 원인으로서 고려상표 군에 포함된 비율을 모니터하는 것도 마케팅 의사결정에 도움이 될 것으로 판단된다. 마지막 으로 제안된 모형(CSEGRD*)에 따라 추정한 준 거가격의 평균은 온스당 7.358센트로서 CSEGRD 모형의 7.071센트보다 높게 나타난 반면에 표준 편차는 1.515센트로서 CSEGRD모형의 2.084센 트에 비해 낮아진 것으로 나타났다. 즉, 고려상 포군의 이질성을 반영하지 않을 경우 실제보다 준거가격은 낮게, 그 편차는 높게 추정되는 것 으로 판단된다. 


\section{V. 결론과 향후 연구방향}

다양한 선행연구에서 준거가격효과는 실증적 지지를 받아온 것이 사실이다. 그러나 대부분의 선행연구에서 간과된 부분은 설명되지 않은 소 비자 반응의 이질성이 준거가격에 반영되어 실 재하지 않는 효과가 마치 유의한 것으로 나타 날 수도 있다는 것이다(Chang et al. 1999; Bell and Lattin 2000). 따라서 latent class approach (Kamakura and Russell 1989; Bucklin and Gupta 1992)나 계층베이즈(hierarchical bayes) 방식(장광필 2001: Chang et al. 1999; Allenby, Arora and Ginter 1998: Gelfand and Smith 1990) 등으로 반응의 이질성을 반영하는 것이 보다 정확한 준거가격효과 추정에 필요하다는 점이 지적되었다. 또 다른 차원의 이질성으로 서. 고려상표군의 이질성이 반영되지 않을 경우 모형에 포함된 변수의 모수추정치에 왜곡현상 이 나타날 수 있음을 Meyer and Kahn(1991) 이 지적한 바 있다. 이러한 선행연구의 문제점 을 고려하여 이 연구에서는 반응의 이질성과 고려상표군의 이질성을 모두 반영한 모형을 적 용함으로써 보다 정확한 준거가격효과의 추정 을 시도하였다. 또한 소비자별 고려상표군의 이 질성을 반영한 준거가격 촉정치를 새롭게 제안 하여 검증하고자 하였다. 실증분석결과, 제안된 준거가격 측정치가 선행연구에서 사용한 측정 치에 비해 모형적합도와 예측타당성을 향상시 키는 것으로 나타났다. 이 결과는 준거가격 형 성과정에도 고려상표군의 이질성이 반영됨을 실증하는 것이다. 고려상표군의 이질성이 반영 될 경우, 선행연구의 준거가격 측정치에 비해
서, 제안된 준거가격 측정치의 평균이 높게 나 타났으며, 표준편차는 감소한 것으로 나타났다. 소비자의 준거가격은 직접 관측할 수 없는 변 수이기 때문에, 이 연구를 비롯하여, 선행연구 에서 서베이를 통해 응답자에게 직접 묻는 방 식이나, 계량경제학적인 방식으로 준거가격을 추정하는 다양한 방법이 시도됐다. 그러나 그러 한 응답이나 추정치가 진정한 준거가격에 접근 하는 것인지에 대한 검증은 여전히 숙제로 남 아있다. 소비자 역시 자신의 정확한 준기가격을 모를 뿐만 아니라, 응답할 능력이 없는 경우라 면 더욱이 불가능한 과제일지도 모른다. 그럼에 도 불구하고 가용한 자료를 통해, 행동과학적으 로 소비자의 실제 브랜드 선택행동에 보다 근 접할 수 있는 준거가격 측정치를 모형화하는 시도는 그 자체로 가치가 있고. 이 분야의 연구 를 진전시키는 중요한 계기가 될 것으로 생각한 다. 이 연구에서 제안된 측정치의 실제적인 적용 측면을 본다면, Greenleaf(1995)의 연구에서처럼. 최적의 가격정책이 손실회피(loss aversion)의 크. 기, 즉, 준거의존모형상의 준거가격에 의존한다 면 제안된 측정치가 유용하게 사용될 수 있을 것으로 판단된다. 왜냐하면 최대화해야할 이익 함수에 포함된 준거가격 측정치의 정확성이 최 적가격결정을 좌우하기 때문이다. 따라서, 준거 가격모형에 근거하여 최적가격을 추정할 경우. 모형자체에 고려상표군과 반응의 이질성을 반 영할 뿐만 아니라, 준거가격 측정치 또한 고려 상표군의 이질성을 반영하는 것이 바람직할 것 으로 판단된다.

〈논문 접수일: 2005. 10. 31〉 〈게재 확정일: 2006. 02. 01〉 


\section{참고문헌}

장광필(2003), “고려상표군을 반영한 자동차 시

장구조 분석모형," 마케팅연구, 18(2), 53-67. 장광필(2001), “모델의 불확실성을 반영한 준거

가격 효과의 모형화," 소비자학연구, 12(2),

101-116.

장광필, 이성호(2003), "Measuring Choice Set-

Based Reference Points: An Empirical Bayes

Approach," 산경논집. 18(1), 235-265.

한상만(1998), “준거효과가 고려상표군 형성에

미치는 영향에 관한 연구: 준거종속적 식역

모델을 중심으로." 경영 학연구, 27(4), 857-

873.

Allenby, Greg M., Neeraj Arora, and James L.

Ginter(1998), "On the Heterogeneity of

Demand," Journal of Marketing Research,

35(August), 384-389.

Bell, David R. and James M. Lattin(2000),

"Looking for Loss Aversion in Scanner

Panel Data: The Confounding Effect of

Price Response Heterogeneity," Marketing

Science, 19(2), 185-200.

Briesch, Richard A., Lakshman Krishnamurthi.

Tridib Mazumdar, and S. P. Raj(1997),

"A Comparative Analysis of Reference

Price Models," Joumal of Consumer Research.

24, 202-214.

Bucklin, Randolph E. and Sunil Gupta(1992),

"Brand Choice, Purchase Incidence, and

Segmentation: An Integrated Modeling

Approach." Journal of Marketing Research,
24(May), 201-215.

Chang, Kwangpil, S. Siddarth, and Charles B. Weinberg(1999), "The Impact of Heterogeneity in Purchase Timing and Price Responsiveness on Estimates of Sticker Shock Effects," Marketing Science, 18(2), 178-192.

Chiang, Jeongwen, Siddartha Chib, and Chakravarthi Narasimhan(1999), "Markov Chain Monte Carlo Models of Consideration Set and Parameter Heterogeneity," Journal of Econometrics, 89(1-2), 223-248.

Gelfand, A. E. and A. F. M. Smith(1990). "Sampling Based Approaches to Calculating Marginal Densities," Joumal of the American Statistical Association, 85, 398-409.

Greenleaf, Eric A.(1995), "The Impact of Reference Price Effects on the Profitability of Price Promotions," Marketing Science, 14(1), 82-104.

Goodhardt, G. J., Ehrenberg A. S. C., and Chatfield, C.(1984), "The Dirichlet: A Comprehensive Model of Buying Behavior," Journal of the Royal Statistical Society, Ser. A, 147, 621-655.

Hardie, B.G.S., E.J. Johnson, and P.S. Fader (1993), "Modeling Lass Aversion and Reference Dependence Effects on Brand Choice." Marketing Science, 12(4), 378-394.

Helson, H.(1964), Adaptation Level Theory, New York: Harper and Row.

Kahneman. Daniel and Amos Tversky(1979), "Prospect Theory: An Analysis of Decision 
Under Risk," Econometrica, 47(March), 263-291.

Kalwani, Manohar U.. Robert J. Meyer, and Donald G. Morrison(1994), "Benchmarks for Discrete Choice Models," Journal of Marketing Research, 31(February), 65-75. Kalwani, Manohar U., Chi Kin Yim, Heikki J. Rinne, and Yoshi Sugita(1990), "A Price Expectations Model of Customer Brand Choice." Journal of Marketing Research, 27(August), 251-262.

Kalyanaram, Gurumurthy and Russell S. Winer (1995), "Empirical Generalizations from Reference Price Research," Marketing Science, 14(3), Part 2 of 2, 161-169.

Kamakura. Wagner A. and Gary J. Russell (1989). “A Probabilistic Choice Model for Market Segmentation and Elasticity Structure," Journal of Marketing Research. 26(November), 379-390.
Meyer, Robert J. and Barbara E. Kahn(1991), "Probabilistic Models of Consumer Choice Behavior," in Handbook of Consumer Behavior, T. S. Robertson and H. Kassarjjan, eds., Englewood Cliffs, NJ: Prentice-Hall Inc. 85-123.

Siddarth, S., Randolph E. Bucklin, and Donald G. Morrison(1995), "Making the Cut: Modeling and Analyzing Choice Set Restriction in Scanner Panel Data," Journal of Marketing Research, 32(August), 255-266.

Tversky, Amos and Daniel Kahneman(1991), "Loss Aversion and Riskless Choice: A Reference-Dependent Model," The Quarterly Journal of Economics, 106(November), 1039-1061.

Winer, R.S.(1986), “A Reference Price Model of Brand Choice for Frequently Purchase Products," Journal of Consumer Research. 13(September), 250-256. 


\title{
Modeling the Effect of Consideration Set-Based Reference Price: Empirical Bayes \& Latent Class Approach
}

Kwangpil Chang*

\begin{abstract}
A couple of previous studies have warned against the use of homogeneous choice models in assessing the effect of reference price since unaccounted for response heterogeneity may result in spurious reference price effects(Chang. Siddarth and Weinberg 1999: Bell and Lattin 2000). According to Meyer and Kahn(1991), not accounting for consideration set heterogeneity may also bias the effect parameters in the choice model. Therefore. failure to account for these two sources of bias, in fact, have cast doubt on the empirical support for reference price effects in general. In view of aforementioned potential sources of bias, the author investigates the robustness of loss aversion effect in the reference-dependent model after accounting for heterogeneity in response as well as consideration set. The proposed model defines individual household's consideration set based on the posterior distribution of preference obtained from the Empirical Bayes approach. In addition. the same posterior distribution is used to form household-specific reference prices. Response heterogeneity correction is carried out via the Latent Class approach. The proposed model outperforms the Reference-Dependent model that includes the reference price measure most often employed in the previous studies. This implies that as a way of simplifying decision task, consumers restrict their consideration set to a subset of available brands not only in making a brand choice but also in forming reference prices.
\end{abstract}

Keywords: reference price, loss aversion, empirical bayes, latent class approach

\footnotetext{
${ }^{*}$ Associate Professor, Faculty of Business Administration, College of Business and Economics, University of Seoul
} 